Lily Griner, Patricia Herron, and Heleni Pedersoli

Sister libraries partners

\title{
Tecnologico de Monterrey, Mexico and University of Maryland-College Park
}

M any of the issues that plague academic librarians transcend geographic borders. Decreasing usage of the library and print resources, increasing student reliance on the Internet and Google for research, increasing need for access to global information, expectations of instant access to information (no matter how obscure), expectations of information access any time, constant library budget cuts, and increasing battles to maintain the professional status of librarians affect all academic librarians, no matter where they are.

The universal nature of these issues offers the opportunity to nd solutions through international partnerships. When people from different cultures and different nations come together to share resources, knowledge and experiences, they can create results beyond the capabilities of any one group. Not only do they learn from each other and discover new ways of using resources, but they come away with renewed energy, increased motivation, and exciting new ideas to take back and explore in their own institutions. As a result of these collaborations, possibilities are envisioned for situations that before seemed unmanageable.

This article describes the experience of one group of librarians from the University of Maryland-College Park (UMD) in developing a partnership with a library at the Tecnologico de Monterrey (Tec) in Monterrey, Mexico. The process began in 2005 and continues today.

\section{The first symposium}

In 2005, ACRL s Board of Directors endorsed a declaration promoting crossnational collaboration among libraries and encouraging institutions to explore sister library partnerships. The main purpose of these partnerships is to build relationships with libraries in other countries/other cultures, with the expectation that knowledge gained from these collaborations can help librarians understand and better serve their own communities. The initial focus of the 2005 declaration was to encourage U.S. librarians to form partnerships with libraries in Mexico.

Simultaneously, but independently, librarians at UMD were cultivating a collaborative relationship with Tec. From the very rst contact, the librarians at both institutions were eager to collaborate. After some discussion, it was agreed that the rst collaboration would be a symposium dealing with academic library user education issues.

In April 2005, four librarians from UMD traveled to Tec for the rst symposium: Maggie Cunningham (user education librarian), Zaida Diaz (business librarian), Lily Griner (business librarian), and Pat Herron (humanities librarian). Patricia Verdines, Ph.D. student at UMD s College of Information Studies on leave from Tec, acted as the facilitator.

The librarians from both institutions had agreed that, as a rst collaboration, this symposium would be an exchange of experiences and approaches to issues on academic library user education. Mexican and U.S. librarians

Lily Griner is business librarian for reference/instruction, social sciences and allied professions team, e-mail: griner@umd.edu; Patricia Herron is librarian for English, Spanish, and Latin American and Latina/o Studies, e-mail: herron@umd.edu; Heleni Pedersoli is librarian for Western European languages, literatures and culture and Latin American Studies at the University of Maryland, e-mail: pedersol@umd.edu

@ 2007 Lily Griner, Patricia Herron, Heleni Pedersoli 
gave presentations on topics that included: the design of library instruction programs, the challenges and bene ts of serving as subject liaisons, issues and experiences in developing relationships with academic departments, and the art of designing Web tools for students and faculty. ${ }^{1}$

By all accounts the symposium was a success. The energy and enthusiasm for a partnership between the libraries increased dramatically as librarians and administrators saw in concrete terms the bene ts of collaboration. On their return, the UMD librarians presented summaries of their experiences to their colleagues and sought to establish communication between UMD and Tec librarians with similar interests and concerns. The Sister Libraries Partnership was formalized a few months later at the ALA Annual Conference in June 2005, with an agreement signed by Dean of UMD Libraries, Charles Lowry, and Director of the Tec Library, Miguel Angel Arreola Gonzalez.

\section{LOEX creates opportunity}

Once formalized, the next step was to keep the partnership active and growing. While email and telephone communication continued between the librarians at the two institutions, the partners needed another opportunity to meet for a face-to-face exchange. That opportunity arose with the Library Orientation Exchange (LOEX) Annual Conference.

LOEX is an educational clearinghouse for library instruction and information literacy. Its annual conference brings together librarians from all over the United States and Canada, as well as other parts of the world, and serves as a conduit for those working in the eld. It is a very important venue for librarians interested in user education issues.

Fortuitously the UMD Library hosted the 2006 LOEX conference in May. Having the conference at the UMD-College Park campus was just the vehicle needed to expand the collaboration. Not only would the conference continue the theme of academic user education and complete the cycle by having the Tec librarians visit the UMD libraries, but it would also open UMD and Tec discussions to a broader range of issues from the U.S. and foreign librarians at LOEX. In February, the UMD librarians invited librarians from Tec to attend the upcoming LOEX conference, to visit the UMD campus and its libraries, and to participate in a formal introduction of the partnership and Tec partners to the library faculty at Maryland.

In early May 2006, two librarians Eloisa Puente Berumen, head of EGADE (Tec s business library), and Cecilia Barragan, head of user education at Tec visited UMD. They attended the LOEX conference, where they joined in the many different energetic and cutting-edge discussions of instruction, assessment, and information literacy.

\section{Introducing the Sister Libraries Partnership}

After the LOEX conference, the Tec librarians met with UMD librarians from several different departments. At the welcoming luncheon the Sister Libraries Partnership was introduced to the UMD library faculty and the faculty from the Spanish and Latin American Studies Department. The Tec librarians described their university, their libraries, and the services they offer. They also spoke of their interest in continuing the Sister Libraries Partnership. Following the formal presentations, everyone brainstormed ideas for moving the partnership forward.

After the visit, the Sister Libraries Partnership gained further momentum from an ACRL seed grant awarded in August 2006 to help build the partnership and exchange ideas as well as personnel. In May 2007, using this grant money, two librarians from Tec, Maria Teresa Solis Adame (director of user services) and Merari Sifuentes (interlibrary loan librarian), visited UMD. For this visit the focus changed to coincide with the visiting librarians interests in space planning and security issues, interlibrary loan (ILL) collaborations, marketing of library services, professional status of the UMD librarians, and the subject liaison system. The agenda for their visit included: 
a welcome luncheon hosted by the dean of the libraries and attended by several library faculty members, the associate provost for international studies, and several faculty members from the Spanish Department;

meeting the coordinator of the communication of ce to discuss efforts to promote the image and visibility of the University Libraries;

meeting the heads of access services and ILL to discuss ILL partnerships;

talking with several subject liaisons about their job and how they promote and market library services to the faculty; and attending a work meeting of the Space Planning Advisory Team, where they observed an actual team meeting in progress and discussed space planning and security issues with the team members.

The hosting librarians from UMD tried to balance the visit with cultural as well as academic pursuits. The Mexican librarians took special tours of the Hispanic Reading Room at the Library of Congress and the Museum of the American Indian. The cultural offering also included an all-day tour of the major sites in Washington, D.C., ending with the changing of the guard at Arlington National Cemetery. To round off their visit, the Tec librarians were treated to sample the world-famous Maryland crabs and the always delicious UM Dairy ice cream.

\section{Learning from each other}

The Sister Libraries Partnership has been an eye-opening experience for both the U.S. librarians and our Mexican counterparts. Beyond the cultural exchange, which has been invaluable, we have received many valuable insights and ideas from each other. For example, at the Tec library s huge computer lab, there are no computers! There are only desks for computers and wireless access. All of the Tec students are required to have laptops. Tec has brokered deals with banks (to provide low-interest loans) and with computer vendors (to provide low prices) to make laptops very affordable. Having students buy their own computers has resulted in a huge saving for the Tec library the library does not have to buy computers for the computer labs, the library does not have to upgrade computers as technology advances, and the library does not have to provide technical support. The students are happy with their laptops, since they can use them for all their educational needs, they can take them home, and they can con gure the computers as they please.

Another out of the box idea observed at Tec is the use of a very visible traf $c$ light in the computer lab as a way to control noise. The light is green when noise level is low, the light turns red when noise level is high

a creative, inexpensive, fun, and functional way to get students attention.

Similarly, the librarians from Tec were impressed with a portal developed by librarians at UMD in collaboration with faculty. The Virtual Business Information Center (VBIC) ${ }^{2}$ is a portal developed by a team of two business librarians, one faculty member from the College of Information Studies, one faculty member from the R. H. Smith School of Business, and a graduate assistant. The portal was developed as a one-stop shopping location for the research needs of UMD business students. VBIC is designed to help students navigate the complex, multifaceted, and sometimes confusing business research environment. Librarians from Tec are exploring ways to use this open text software as a template for their business school students.

Finally, the Sister Libraries experience has provided opportunities to not only learn from each other about how to deal with challenging library issues, but as an added bonus we have experienced each other s cultures and have formed lasting friendships across the border. We see our current collaborations as beginning of a long and productive association. As a further demonstration of our commitment to the Sister Libraries Partnership, we are in the process of devising a pilot ILL program between the two schools and to nd and share ways to better market the library as well as the professionalism of librarians to faculty and the campus community. We are very pleased

(continues on page 589) 
reviews of recent publications in the area of history. While the focus is not on the classical era in particular, a signi cant portion of the books address that period. Access: http://www.h-net.org/reviews.

Leeds International Classical Studies. This journal, according to its Web site, is a peer-reviewed on-line journal, associated with the Leeds International Classics Seminar. It publishes articles and interim discussion papers on all aspects of Greek and Roman antiquity, and of the history of the classical tradition. The journal is freely available online and has archives back to 2002. Access: http://www.leeds.ac.uk/classics/lics.

TOCS-IN. As its Web site indicates, TOCS-IN provides the tables of contents of a selection of Classics, Near Eastern Studies, and Religion journals, both in text format and through a Web search program. Where possible, links are given with articles of which the full text or an abstract is available online (about 15\%). While this is not a free online journal, TOCS-IN provides free access to journal information and includes some free full-text articles, as well. Access: http://www.chass.utoronto.ca/amphoras /tocs.html.

The resources addressed above represent some of the best available in the area of classical studies, but they by no means cover the topic completely. The resources might best be seen as useful starting points for locating the abundance of material online in this large subject area. $n$

("Sister libraries..." continued from page 568) with the Sister Libraries Partnership and very excited about exploring new opportunities and continually growing our partnership.

\section{Notes}

1. The presentation abstracts and PowerPoint slides can be viewed at the conference Web site: www.lib.umd.edu/MCK /monterrey2005.html.

2. The Virtual Business Information Center (VBIC) is at www.vbic.umd.edu. $\varkappa$

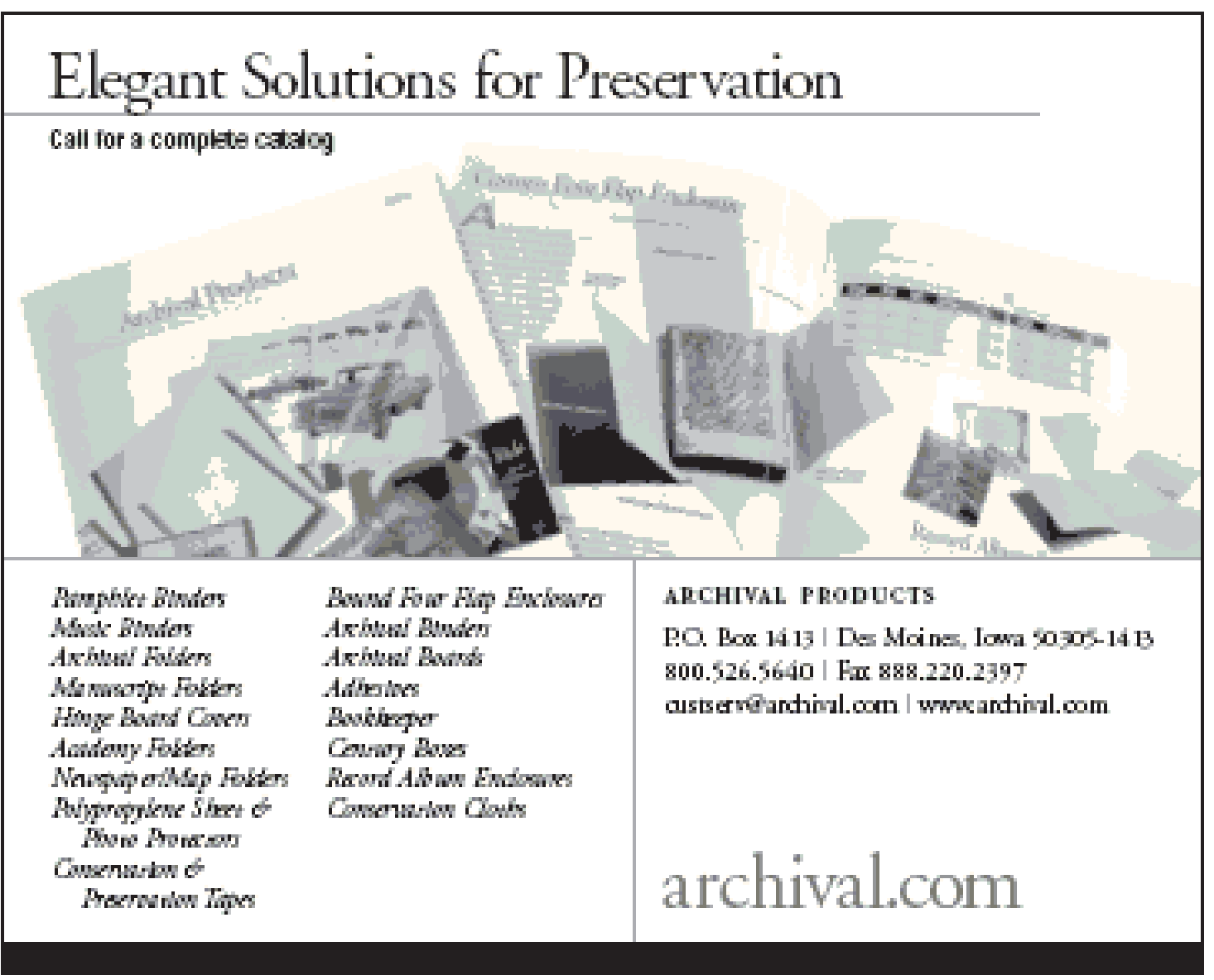

